\title{
Real-World Treatment Persistence with Biologic Disease-Modifying Antirheumatic Drugs Among German Patients with Psoriatic Arthritis-A Retrospective Database Study
}

\author{
Philipp Sewerin (D) Kathrin Borchert - Dominic Meise • \\ Matthias Schneider · Jörg Mahlich
}

Received: December 11, 2020 / Accepted: January 29, 2021 / Published online: February 21, 2021

(C) The Author(s) 2021

\section{ABSTRACT}

Introduction: To investigate drug survival for biologic disease-modifying antirheumatic drugs (bDMARDs) in a real-world cohort of German adult biologic-naïve patients with psoriatic arthritis (PsA).

Methods: Claims data for patients with a diagnosis of PsA, a bDMARD claims record (index date) between 1 January 2014 and 31 December 2017, and no bDMARD prescription for 365 days before the index date were retrospectively analyzed. The primary outcomes were the overall and individual bDMARD persistence

Supplementary Information The online version contains supplementary material available at https:// doi.org/10.1007/s40744-021-00286-z.

P. Sewerin $(\bowtie) \cdot$ M. Schneider

Department and Hiller Research Unit for

Rheumatology, UKD, Heinrich-Heine University, Düsseldorf, Germany

e-mail: philipp.sewerin@med.uni-duesseldorf.de

K. Borchert · D. Meise

Xcenda GmbH, Hannover, Germany

J. Mahlich

Health Economics and Outcomes Research, Janssen,

Pharmaceutical Companies of Johnson \& Johnson,

Neuss, Germany

J. Mahlich

Düsseldorf Institute of Competition Economics

(DICE), University of Düsseldorf, Düsseldorf,

Germany rates over 12 months. Nonpersistence was defined as a treatment gap exceeding the days of supply plus 60 days or switching to a bDMARD other than the index therapy. Sensitivity analysis was performed, wherein the treatment gap was found to vary depending on the bDMARD regimen. Kaplan-Meier curves were plotted to determine persistence; the log-rank test was used to evaluate differences in the persistence rate. Factors associated with treatment discontinuation were evaluated using Cox regression analysis.

Results: Among 10,954 patients with a PsA diagnosis, 348 were eligible. The overall bDMARD persistence rate was $57.5 \%$; individual bDMARD persistence rates were $81.3 \%$ for ustekinumab, $66.7 \%$ for infliximab, and $60.0 \%$ for golimumab. The mean (SD) overall persistence with bDMARDs was 289 (103) days; the mean persistence was 334 (72) days for ustekinumab, 309 (82) days for golimumab, and 305 (92) days for infliximab. The main reasons for nonpersistence were switching to another bDMARD (15.8\%) and treatment discontinuation $(26.7 \%)$. Male gender was significantly associated with a lower risk of treatment discontinuation (hazard ratio $0.54,95 \%$ confidence interval $0.39-0.77 ; \quad P<0.001)$. The sensitivity analysis yielded similar results.

Conclusion: The one-year persistence rate for bDMARDs in German PsA patients is modest, although the persistence rate depends on the bDMARD considered. 
Keywords: Biologic

disease-modifying antirheumatic drugs; Germany; Persistence; Psoriatic arthritis

\section{Key Summary Points}

Persistence with biologic diseasemodifying antirheumatic drugs is moderate in German patients with psoriatic arthritis.

The persistence rate depends on the biologic disease-modifying antirheumatic drug considered.

Male gender is associated with a lower risk of treatment discontinuation.

\section{DIGITAL FEATURES}

This article is published with digital features, including a summary slide, to facilitate understanding of the article. To view digital features for this article go to https://doi.org/10.6084/ m9.figshare.13636769.

\section{INTRODUCTION}

Psoriatic arthritis (PsA) is a common chronic inflammatory rheumatic disease characterized by pain, stiffness, swollen joints, joint erosion, and bone formation, as well as psoriasis as a concomitant condition [1, 2]. The age-standardized prevalence of PsA in Germany from 2009 to 2012 was reported to be 1.8-2.1 per 100,000 in men and $2.1-2.5$ per 100,000 in women, resulting in an estimated 200,000 patients with PsA living in Germany in 2018 [3]. PsA negatively impacts health-related quality of life (HRQoL) due to fatigue, impairment of daily functions and ability to work, and diminished social participation $[4,5]$. PsA has also been associated with a high economic burden. Jacob et al. [6] analyzed German claims data and reported average healthcare costs in treated prevalent patients with PsA to be $€ 5557$ within a year of diagnosis and $€ 5761$ in the second year. A similar claims data analysis by Sondermann et al. [7] revealed that the average cost of conventional synthetic disease-modifying antirheumatic drugs (csDMARDs) was $€ 322$ per patient per year, and the average cost of biologic DMARDs (bDMARDs) was $€ 15,304$ per patient per year.

Treatment options for PsA include traditional symptomatic therapies such as nonsteroidal anti-inflammatory drugs and glucocorticoids; DMARDs such as methotrexate, leflunomide, and cyclosporine; bDMARDs such as tumor necrosis factor inhibitors (TNFis) and interleukin-12/23 or interleukin-17 inhibitors; or targeted synthetic DMARDs (tsDMARDs) such as phosphodiesterase-4 or Janus kinase inhibitors [8-10]. For patients with active PsA refractory to conventional drugs or those with a poor prognosis, treatment with tsDMARDs or bDMARDs is recommended [10]. In Germany, most patients with PsA were treated systemically $(53.7 \%)$; most of those patients were treated with DMARDs (72.1\%), while $20.9 \%$ were treated with a combination of DMARDs and biologics [7]. Currently, nine bDMARDs (etanercept, infliximab, adalimumab, certolizumab pegol, golimumab, ustekinumab, secukinumab, abatacept, and ixekizumab) and two tsDMARDs (apremilast and tofacitinib) are approved in Germany for the treatment of patients with PsA. Apremilast has been available since 2015, while abatacept, ixekizumab, and tofacitinib have been available since 2018 .

Persistence with bDMARDs and tsDMARDs, i.e., the time interval from initiation to discontinuation of treatment [11], varies with the treatment under investigation and with the type of health center and the country considered [12-14]. In Germany, the persistence rate for patients with PsA who were prescribed biologics was reported to be $57.9 \%$ after 1 year [13] and $33.2 \%$ after 5 years [15]. However, these persistence rates are for prescriptions of biologics as a class, not for individual biologics. Studies from other countries have reported that persistence rates of biologics that are used to treat PsA vary depending on the drug prescribed at the index date $[12,14]$, but corresponding data for Germany are still awaited, despite their 
importance for clinical and health economic decision-making. To address this knowledge gap, we evaluated the real-world bMARD persistence rate of patients with PsA using data from a large German claims database.

\section{METHODS}

\section{Data Source}

Deidentified patient data were obtained from the Institute for Applied Health Research Berlin (InGef) research database. The authors had the permission to use this private dataset. This database comprises comprehensive longitudinal patient-level electronic records of health insurance claim information such as inpatient and outpatient treatments, prescription drugs, and other health-related claims data for about 4 million members of the German statutory health insurance (SHI) system, who were structured to represent the German population in terms of age and gender according to the Federal Office of Statistics (DESTATIS) [16]. The representativeness of the database compared to the general German population in terms of morbidity, mortality, and drug usage has been externally validated [17]. In Germany, around $90 \%$ and $10 \%$ of the population are covered by statutory health insurance and private insurance, respectively. The InGef database has been extensively utilized for health services research $[18,19]$. Ethics approval was not required, as this study used anonymized German claims data.

\section{Study Population}

This retrospective cohort study spanned from 1 January 2013 to 31 December 2018. Patients who were classified with PsA according to the International Classification of Diseases German Modification, 10th Revision (ICD-10-GM) code L40.5 in combination with M07.0/07.1/07.2/ 07.3 (Table S1 in the "Supplementary Information") in the inpatient setting (primary or secondary diagnosis) or outpatient setting (verified diagnosis) and who had a claims record of biologic treatment licensed for PsA as per Anatomical Therapeutic Chemical (ATC) classification codes (Table S2 in the "Supplementary Information") between 1 January 2014 and 31 December 2017 were included. The index date was defined as the first observed prescription (i.e., the dispense date) of the bDMARD. A diagnosis of PsA and a biologic claim in the same quarter (the "index quarter"), age $\geq 18$ years old in the index quarter, biologic-naïve status at the index date, and the presence of at least 365 days of continuous enrollment prior to and after the index date were essential for inclusion in the study. Biologic-naïve patients were defined as those who had no prescription record for any PsA-licensed biologic at any strength during the first 12 months of their observation period ("washout"). Patients with Crohn's disease (ICD-10 K50), ulcerative colitis (ICD-10 K51), ankylosing spondylitis (ICD-10 M45), or rheumatoid arthritis (ICD-10 M05-M07) were excluded, as were patients with two different bDMARD index prescriptions on the same day (Fig. 1).

\section{Covariates}

Age, gender, insurance status, degree of polypharmacy, use of corticosteroids, diagnosis of psoriasis in the same quarter as the index event, and the Charlson Comorbidity Index (CCI) [20] were the baseline covariates of interest. Polypharmacy and corticosteroid prescriptions were assessed based on ATC codes for specific comedications used in the 12-month pre-index period (Table S3 in the "Supplementary Information"). Psoriasis was diagnosed using the ICD-10-GM codes L40.0-L40.4, L40.8, and L40.9. The CCI included 19 comorbidities as given in Table S4 of the "Supplementary Information" (myocardial infarction, congestive heart failure, peripheral vascular disease, cerebrovascular disease, dementia, chronic pulmonary disease, rheumatic disease, peptic ulcer disease, mild liver disease, diabetes without chronic complication, diabetes with chronic complication, hemiplegia or paraplegia, renal disease, tumors without metastasis, lymphoma, leukemia, moderate or severe liver disease, 


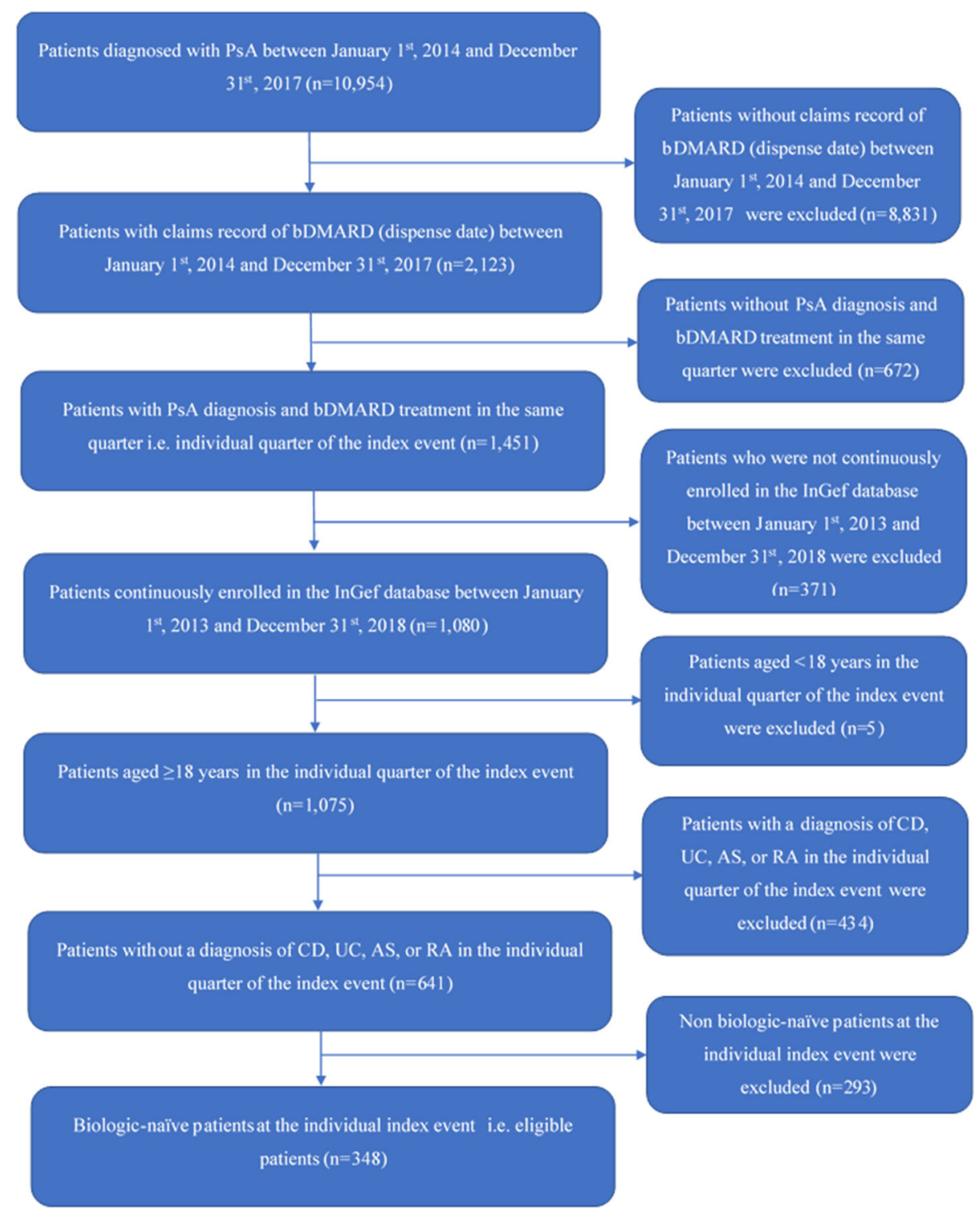

Fig. 1 Dataset for analysis. $A S$ ankylosing spondylitis, $b D M A R D$ biologic disease-modifying antirheumatic drug, $C D$ Crohn's disease, $P s A$ psoriatic arthritis, $R A$ rheumatoid arthritis, $U C$ ulcerative colitis

metastatic solid tumors, and AIDS/HIV), and a weight of between 1 and 6 was assigned to each comorbidity. A higher CCI indicates greater morbidity of the patient.

\section{Outcomes}

The primary outcome was the persistence rate with biologics over 12 months in the post-index period. Kaplan-Meier curves were used to assess the overall bDMARD persistence as well as the persistence with each individual bDMARD. The persistence period was defined as the time from treatment initiation (index date) until discontinuation of the index biologic or the treatment was switched to another biologic during followup, whichever came first. Nonpersistence occurred if (1) a gap exceeding 60 days (grace period) after the end of supply of the index bDMARD was found or (2) the patient switched from the index bDMARD to one or more nonindex treatments. This definition of drug 
survival was consistent with that employed in other studies of persistence [21-23]. Days of supply were calculated based on the daily defined doses (DDD) as reported by the World Health Organization for each bDMARD (Table S2 in the "Supplementary Information") [24]. Some biologics require an initiation phase with shorter treatment intervals, so the recommended dosing during the initiation phase can differ from the DDD. Stockpiling of biologic compounds was not allowed in the calculation of days of supply (renewal of a prescription during the days of supply of the first prescription set the days of supply of the first prescription to zero).

For example, an adalimumab prescription administered every two weeks would be renewed within 14 days. If it was not renewed, the gap began on day 15 and accounted for 60 days of no medical supply. In this case, the patient was still considered persistent if the prescription was renewed 74 days after the initial prescription $(14+60=74)$, but they were considered to have discontinued after 74 days without a refill. If a patient with adalimumab as the index treatment received another biologic prescription of, for example, etanercept after 15 days, the patient was considered a switcher. If the etanercept prescription was filled on day 75 after the index prescription, the patient was considered to have discontinued.

\section{Sensitivity Analysis}

In the sensitivity analysis, the determination of discontinuation was altered by defining a treatment gap based on the particular regimen of the maintenance dosage of each bDMARD. Consequently, the treatment gap varied and was assessed individually for each bDMARD after taking the respective product information for the bDMARD (Table S5 in the "Supplementary Information") into account. For example, an adalimumab prescription administered every two weeks had an individual gap of 14 days based on the recommended dose. In this case, the patient was considered persistent if the prescription was renewed 28 days after the initial prescription $(14+14=28)$, and was considered to have discontinued after 28 days without a refill. If a patient with adalimumab as the index treatment received another biologic prescription of, for instance, etanercept after 15 days, the patient was considered a switcher. If the etanercept prescription was filled on day 29 after the index prescription, the patient was considered to have discontinued.

\section{Statistical Analysis}

Means and standard deviations were calculated for continuous variables, and counts and percentages were calculated for categorical variables. Kaplan-Meier curves were plotted to show the overall persistence with bDMARDs and the persistence with each bDMARD. The log-rank test was used to test for statistically significant differences $(P<0.05)$ between the persistence curves. Cox regression analysis was performed to examine the association between variables such as age, gender, CCI, degree of polypharmacy, insurance status, use of corticosteroids, and presence or absence of a psoriasis diagnosis in the same quarter as the index event. The parameter estimate, standard error, $Z$ value, $\operatorname{Pr}>Z$, hazard ratio (HR), and 95\% confidence interval (CI) were determined for each variable included in the Cox regression. $P<0.05$ was considered statistically significant. All analyses were undertaken using R software version 3.5.0.

\section{RESULTS}

\section{Population Characteristics}

Among the 10,954 patients diagnosed with PsA, 348 were eligible for the study (Fig. 1). The final sample included 105 patients on adalimumab, 29 on certolizumab pegol, 100 on etanercept, 20 on golimumab, 9 on infliximab, 53 on secukinumab, and 32 on ustekinumab. Table 1 shows the baseline characteristics. The mean (SD) age of the patients was 50.4 (12.4) years, and the majority of the patients (80.2\%) were $\leq 60$ years old. Most of the patients were full members $(73.3 \%)$ as compared to family- 
insured $(6 \%)$ or pensioners $(20.7 \%)$. The mean (SD) CCI score of the patients was 0.99 (1.24), and the majority of the patients had a CCI score $\leq 2(89.1 \%)$. Most of the patients were prescribed 1-2 medications (68.7\%), and the mean (SD) number of medications among the patients was 1.7 (1.03). Baseline characteristics were balanced across the different compounds (Table S6 in the "Supplementary Information").

\section{Persistence}

Table 2 shows the persistence rates. The 12-month overall bDMARD persistence rate was $57.5 \%$, with a mean (SD) persistence of 289 (103) days. Figure 2 displays the overall Kaplan-Meier drug survival curve. Major reasons for nonpersistence were treatment discontinuation $(26.7 \%)$ and switching to another therapy $(15.8 \%)$. Patients most often switched to secukinumab $(3.2 \%)$ or adalimumab or certolizumab pegol (both 2.9\%). Among the bDMARDs, ustekinumab (81.3\%), infliximab $(66.7 \%)$, and golimumab (60.0\%) had high persistence rates (Table 2 and Fig. 3). Mean (SD) persistence (measured in days on treatment) was 334 (72) for ustekinumab, 309 (82) for golimumab, and 305 (92) days for infliximab. The ustekinumab group showed a significantly longer duration of persistence than the other bDMARD groups except for golimumab and infliximab $(P<0.05$ for all). Nonpersistence was highest in patients on etanercept $(49.0 \%)$ and lowest in patients on ustekinumab (18.8\%). Most patients discontinued their treatment rather than switching to another biologic. Patients on secukinumab were most likely to discontinue treatment (41.5\%), while those on ustekinumab were least likely to discontinue treatment $(15.6 \%)$. Patients on certolizumab pegol switched therapy the most (24.1\%) (Table 2).

In the sensitivity analysis, the 12-month overall bDMARD persistence rate was $57.8 \%$, with a mean (SD) persistence of 285 (110) days; among the individual bDMARDs, ustekinumab $(87.5 \%)$, infliximab (66.7\%), and golimumab (65.0\%) had high persistence rates (Table S7 and Fig. S1 in the "Supplementary Information"). A high mean (SD) persistence (in days on treatment) was observed for ustekinumab: 344 (59); golimumab: 321 (72); and infliximab: 316 (79). The ustekinumab group showed significantly greater persistence than the other bDMARD groups except for golimumab and infliximab $(P<0.001$ for all). Patients on secukinumab were most likely to discontinue treatment $(39.6 \%)$, while those on golimumab, infliximab, and ustekinumab were least likely to discontinue treatment $(<5$ patients).

\section{Factors Affecting Risk of Treatment Discontinuation}

The results of the Cox regression analysis are presented in Table 3. Male gender was significantly associated with a lower risk of treatment discontinuation (HR 0.54, 95\% CI 0.39-0.77; $P<0.001)$. Although patients with a higher degree of polypharmacy or an insurance status of 'full member' or 'pensioner' had a higher risk of treatment discontinuation, these risk increases were not statistically significant (Table 3). Male gender was significantly associated with a lower risk of treatment discontinuation in the sensitivity analysis too (HR 0.51, 95\% CI $0.36-0.73 ; P<0.001$ ) (Table S8 in the "Supplementary Information").

\section{DISCUSSION}

The overall 12-month persistence rates observed in the current study (primary analysis: 57.5\%; sensitivity analysis: $57.8 \%$ ) were moderate but were similar to the results of claims data-based studies from Germany $(58.7 \%$ and $71.4 \%)$ $[13,15]$, Brazil $(66.4 \%)$ [14], and the US $(43.4 \%$ and $44.5 \%)$ [12, 25] covering various time periods, as well as that in a systematic review by Murage et al. (61\%) [26]. Although the current study did not evaluate persistence beyond 12 months, previous research has shown that persistence rates decrease with time. Walsh et al. reported a decrease in persistence rate from $44.5 \%$ after 12 months [25] to $19.7 \%$ after 24 months [27] of follow-up. A change in persistence rate after an even longer period of time was reported by Jacob et al. [15] (from 71.4\% 
Table 1 Baseline characteristics

\begin{tabular}{|c|c|c|c|}
\hline Parameter & $\begin{array}{l}\text { Total } \\
(n=348)\end{array}$ & $\operatorname{Men}(n=184)$ & $\begin{array}{l}\text { Women } \\
(n=164)\end{array}$ \\
\hline Age in years, mean (SD) & $50.4(12.4)$ & $50.5(11.7)$ & $50.4(13.2)$ \\
\hline \multicolumn{4}{|l|}{ Age groups, $n(\%)$} \\
\hline$\leq 60$ & $279(80.2)$ & $149(81.0)$ & $130(79.3)$ \\
\hline $61-70$ & $49(14.1)$ & $25(13.6)$ & $24(14.6)$ \\
\hline$>70$ & $20(5.8)$ & $10(5.4)$ & $10(6.1)$ \\
\hline \multicolumn{4}{|l|}{ Insurance status, $n(\%)$} \\
\hline Full member & $255(73.3)$ & $149(81.0)$ & $106(64.6)$ \\
\hline Family-insured & $21(6.0)$ & $<5(-)$ & $20(12.2)$ \\
\hline Pensioner & $72(20.7)$ & $34(18.5)$ & $38(23.2)$ \\
\hline CCI score, mean (SD) & $0.99(1.24)$ & - & - \\
\hline \multicolumn{4}{|l|}{ CCI score, $n(\%)$} \\
\hline$\leq 2$ & $310(89.1)$ & $162(88.0)$ & $148(90.2)$ \\
\hline $3-5$ & $36(10.3)$ & $22(12.0)$ & $14(8.5)$ \\
\hline$>5$ & $<5(-)$ & 0 & $<5(-)$ \\
\hline Degree of polypharmacy, mean (SD) & $1.7(1.03)$ & - & - \\
\hline \multicolumn{4}{|l|}{ Degree of polypharmacy, $n(\%)$} \\
\hline 0 & $46(13.2)$ & $24(13.0)$ & $22(13.4)$ \\
\hline $1-2$ & $239(68.7)$ & $132(71.7)$ & $107(65.2)$ \\
\hline $3-5$ & $63(18.1)$ & $28(15.2)$ & $35(21.3)$ \\
\hline Corticosteroid prescriptions/patient, mean (SD) & $1.3(1.9)$ & & \\
\hline \multicolumn{4}{|l|}{ Corticosteroid prescribed, $n(\%)$} \\
\hline No & $184(52.9)$ & $103(56.0)$ & $81(49.4)$ \\
\hline Yes & $164(47.1)$ & $81(44.0)$ & $83(50.6)$ \\
\hline \multicolumn{4}{|c|}{ Psoriasis diagnosis in the same quarter as the index event, $n(\%)$} \\
\hline No & $62(17.8)$ & $26(14.1)$ & $36(22.0)$ \\
\hline Yes & $286(82.2)$ & $158(85.9)$ & $128(78.0)$ \\
\hline
\end{tabular}

Patient counts below 5 are reported as $<5$ due to data protection regulations $C C I$ Charlson Comorbidity Index, $S D$ standard deviation

after 12 months to $33.2 \%$ after 60 months of follow-up). The variation in persistence rate among these studies can be attributed to the different regions considered, clinical practices applied, databases employed, and inclusion criteria used. In the primary and sensitivity analyses of the current study, ustekinumab $(81.3 \%$ and $87.5 \%)$, infliximab (66.7\% for both), 
Table 2 Persistence rates for biologic compounds at 12 months

\begin{tabular}{|c|c|c|c|c|c|c|c|c|}
\hline Persistence & $\begin{array}{l}\text { Total } \\
(n=348)\end{array}$ & $\begin{array}{l}\text { ADA } \\
(n=105)\end{array}$ & $\begin{array}{l}\text { CER } \\
(n=29)\end{array}$ & $\begin{array}{l}\text { ETA } \\
(n=100)\end{array}$ & $\begin{array}{l}\text { GOL } \\
(n=20)\end{array}$ & $\begin{array}{l}\text { INF } \\
(n=9)\end{array}$ & $\begin{array}{l}\text { SEC } \\
(n=53)\end{array}$ & $\begin{array}{l}\text { UST } \\
(n=32)\end{array}$ \\
\hline $\begin{array}{l}\text { Persistence, mean no. } \\
\text { of days (SD) }\end{array}$ & $289(103)$ & $285(107)^{*}$ & $\begin{array}{l}273 \\
(120)^{*}\end{array}$ & $\begin{array}{l}276 \\
(110)^{* *}\end{array}$ & $309(82)$ & $\begin{array}{l}305 \\
\quad(92)\end{array}$ & $291(92)^{*}$ & $334(72)$ \\
\hline Did not persist, $n(\%)$ & $148(42.5)$ & $44(41.9)$ & $14(48.3)$ & $49(49.0)$ & $8(40.0)$ & $<5(-)$ & $24(45.3)$ & $6(18.8)$ \\
\hline Discontinued, $n(\%)$ & $93(26.7)$ & $22(21.0)$ & $7(24.1)$ & $30(30.0)$ & $5(25.0)$ & $<5(-)$ & $22(41.5)$ & $5(15.6)$ \\
\hline Switched, $n(\%)$ & $55(15.8)$ & $22(21.0)$ & $7(24.1)$ & $19(19.0)$ & $<5(-)$ & $<5(-)$ & $<5(-)$ & $<5(-)$ \\
\hline \multicolumn{9}{|l|}{$\begin{array}{l}\text { bDMARD after first } \\
\text { switch, } n(\%)\end{array}$} \\
\hline $\mathrm{ABA}$ & $<5(-)$ & 0 & $<5(-)$ & 0 & 0 & 0 & 0 & 0 \\
\hline $\mathrm{ADA}$ & $10(2.9)$ & 0 & $<5(-)$ & $5(5.0)$ & $<5(-)$ & 0 & 0 & $<5(-)$ \\
\hline CER & $10(2.9)$ & $<5(-)$ & 0 & $<5(-)$ & 0 & $<5(-)$ & $<5(-)$ & 0 \\
\hline ETA & $8(2.3)$ & $7(6.7)$ & $<5(-)$ & 0 & 0 & 0 & 0 & 0 \\
\hline GOL & $<5(-)$ & $<5(-)$ & 0 & 0 & 0 & 0 & 0 & 0 \\
\hline INF & $<5(-)$ & $<5(-)$ & 0 & $<5(-)$ & 0 & 0 & 0 & 0 \\
\hline IXE & $<5(-)$ & 0 & 0 & $<5(-)$ & $<5(-)$ & 0 & $<5(-)$ & 0 \\
\hline SEC & $11(3.2)$ & $<5(-)$ & $<5(-)$ & $6(6.0)$ & 0 & 0 & 0 & 0 \\
\hline UST & $7(2.0)$ & $<5(-)$ & $<5(-)$ & $<5(-)$ & $<5(-)$ & 0 & 0 & 0 \\
\hline Persisted, $n(\%)$ & $200(57.5)$ & $61(58.1)$ & $15(51.7)$ & $51(51.0)$ & $12(60.0)$ & $6(66.7)$ & $29(54.7)$ & $26(81.3)$ \\
\hline
\end{tabular}

Patient counts below 5 are reported as $<5$ due to data protection regulations

$A B A$ abatacept, $A D A$ adalimumab, CER certolizumab pegol, ETA etanercept, $G O L$ golimumab, INF infliximab, IXE ixekizumab, $S D$ standard deviation, $S E C$ secukinumab, UST ustekinumab

${ }^{*} P<0.05$ and ${ }^{* *} P<0.01$ compared with ustekinumab using the log-rank test

and golimumab (60.0\% and 65.0\%) had high persistence rates. Walsh et al. also reported that $50.6 \%$ of patients persisted with ustekinumab after 12 months [25] and 27.2\% persisted after 24 months [27] of follow-up. High persistence rates with ustekinumab have been consistently observed in patients with psoriasis regardless of the study design or operationalization of persistence [22, 28-31]. Data from big European registries such PSOLAR, DERMBIO, and BABDIR [32-35] as well as a recent meta-analysis support this conclusion [36]. The high persistence rate for ustekinumab may be attributed to its low immunogenicity, high efficacy, convenient administration, and favorable risk profile [37].
Consistent with previous research, in the current study, only male gender was observed to be significantly associated with a lower risk of treatment discontinuation in both the primary and sensitivity analyses. Da Silva et al. [14] evaluated a historical cohort of Brazilian patients with PsA who were treated with TNFi and reported that female gender was associated with medication nonpersistence (HR 2.65, 95\% CI 1.4-5.0; $P=0.003)$. Similar results were reported by Stober et al. [38] in a single-center retrospective cohort study of patients with PsA initiating TNFi therapy (HR 2.57, 95\% CI $1.3-5.2 ; P=0.01$ ). Previous research has also reported other factors such as age $\leq 30$ years (HR 1.29, 95\% CI 1.1-1.5; $P=0.002$ ) [15] and 

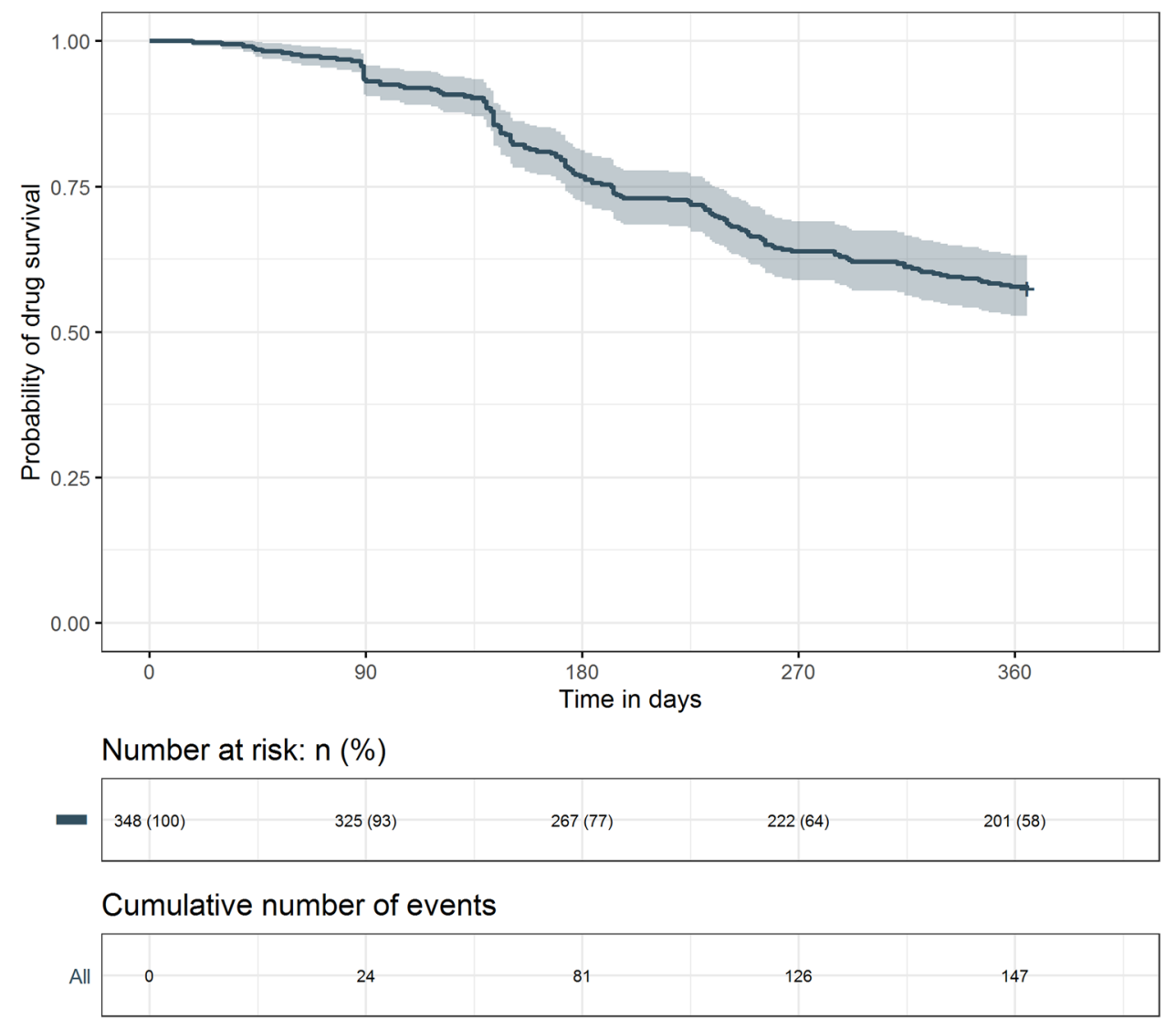

Fig. 2 Kaplan-Meier drug survival curve at 12 months for all biologics combined

any baseline metabolic syndrome-related comorbidity (HR 2.65, 95\% CI 1.2-5.7; $P=0.01$ ) to be associated with a lack of persistence with bDMARDs in patients with PsA [38].

The persistence rates observed in the current study suggest that usage of bDMARDs could result in better clinical and patient outcomes. However, evidence supporting such an association in the domain of PsA is unavailable. Nevertheless, there are sufficient data in other therapeutic areas to demonstrate the benefits (reduced disease activity and improved HRQoL) that result from persisting with the prescribed medication [39-41].

A recent network meta-analysis reported that bDMARDs were clinically effective and safe to use for the treatment of active PsA [42]. Moreover, continuous treatment with bDMARDs has also been reported to enhance HRQoL $[43,44]$ and reduce impairment of work productivity $[45,46]$. The direct costs of PsA in Europe vary from US $\$ 3,693$ to US $\$ 8,871$ per patient-year, with biologics comprising a major proportion of the direct costs [47]. However, the usage and consequent cost of biologics are balanced by the resulting significant improvements in HRQoL and decreased work productivity losses, which result in reduced indirect costs $[44,48]$. Evidence from France suggests that increased persistence with bDMARDs may result in fewer healthcare visits and costs, ultimately reducing the clinical and economic burden [49]. Therefore, further research on the impact of treatment persistence on health resource utilization in Germany is needed to quantify its economic benefits.

\section{Limitations}

There are a few limitations of the present study. This study is based on anonymized health insurance claims data obtained from the InGef 


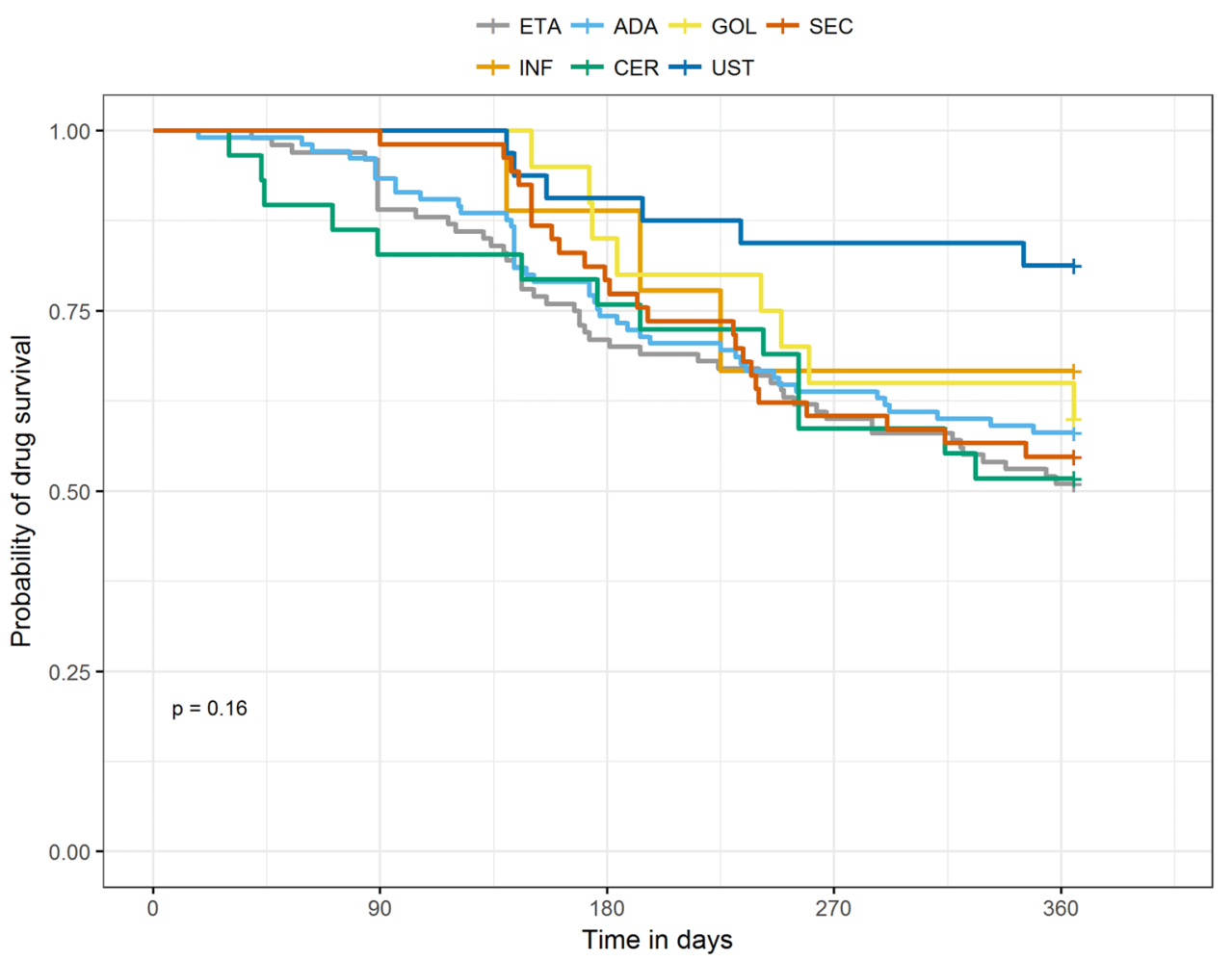

Number at risk: $\mathrm{n}(\%)$

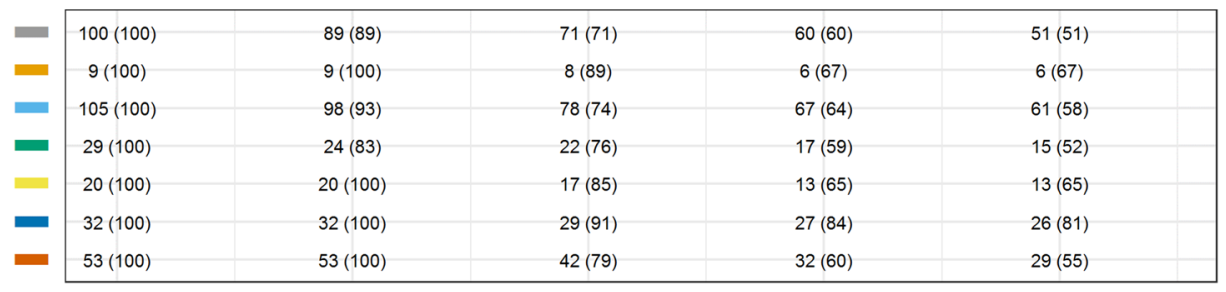

Fig. 3 Kaplan-Meier drug survival curves at 12 months for individual biologics: $A D A$ adalimumab, $C E R$ certolizumab pegol, ETA etanercept, GOL golimumab, INF infliximab, SEC secukinumab, UST ustekinumab

database. Such data are routinely collected by the SHI for billing, not research, purposes. Hence, appropriate data protection provisions are implemented when using SHI claims data; moreover, single-patient case studies are not possible. As the database solely contains claims data, only recorded services can be reimbursed by the SHI. Consequently, the database does not provide clinical values (e.g., laboratory test data) or services that are not covered by the SHI catalog of benefits. Additionally, the claims data do not include data on disease severity or the quality of life of the patient, personally identifiable information, data on the efficacy and safety of prescribed medications, and data on over-the-counter medications. Therefore, classification criteria such as the Classification Criteria for Psoriatic Arthritis (CASPAR) [50] are unavailable for the entire study population. Due to the nature of health claims data, it is possible that a diagnosis of PsA was reported due to a coding error or misclassification. We included patients who did not receive biologics for 365 days before the index date; however, it is possible that some patients may have been treated with biologics prior to the 365-day washout period. The clinical domains highlighted by the Group for Research and Assessment of Psoriasis and Psoriatic Arthritis (GRAPPA) [51] were not assessed during the 
Table 3 Cox regression

\begin{tabular}{|c|c|c|c|c|}
\hline Parameter & Estimate (SE) & $Z$ & $\operatorname{Pr}>Z$ & Hazard ratio $(95 \% \mathrm{CI})$ \\
\hline \multicolumn{5}{|l|}{ Age group (years) } \\
\hline$\leq 60$ & $-0.11(0.43)$ & -0.25 & 0.80 & $0.90(0.39-2.08)$ \\
\hline $61-70$ & $-0.21(0.42)$ & -0.51 & 0.61 & $0.81(0.36-1.84)$ \\
\hline$>70$ & Reference & & & \\
\hline \multicolumn{5}{|l|}{ Gender } \\
\hline Male & $-0.61(0.18)$ & -3.45 & $<0.001$ & $0.54(0.39-0.77)$ \\
\hline Female & Reference & & & \\
\hline CCI & $-0.12(0.07)$ & -1.60 & 0.11 & $0.89(0.77-1.03)$ \\
\hline \multicolumn{5}{|c|}{ Degree of polypharmacy } \\
\hline 0 & Reference & & & \\
\hline $1-2$ & $0.21(0.27)$ & 0.81 & 0.42 & $1.24(0.74-2.09)$ \\
\hline $3-5$ & $0.40(0.31)$ & 1.29 & 0.20 & $1.50(0.81-2.77)$ \\
\hline \multicolumn{5}{|l|}{ Insurance status } \\
\hline Full member & $0.14(0.34)$ & 0.42 & 0.67 & $0.16(0.59-2.26)$ \\
\hline Pensioner & $0.14(0.41)$ & 0.33 & 0.74 & $1.15(0.51-2.57)$ \\
\hline Unknown & - & - & - & - \\
\hline Family-insured & Reference & & & \\
\hline \multicolumn{5}{|c|}{ Corticosteroid prescription } \\
\hline No & Reference & & & \\
\hline Yes & $0.22(0.17)$ & 1.29 & 0.20 & $1.25(0.89-1.76)$ \\
\hline \multicolumn{5}{|c|}{ Psoriasis diagnosis in the same quarter as the index event } \\
\hline No & Reference & & & \\
\hline Yes & $0.19(0.22)$ & 0.86 & 0.39 & $1.21(0.78-1.88)$ \\
\hline
\end{tabular}

$C C I$ Charlson Comorbidity Index, $C I$ confidence interval, $S E$ standard error

course of the study and could be assessed only approximately via ICD-10-GM diagnoses, as specific ICD-10-GM diagnosis codes are unavailable and not routinely coded by physicians. Moreover, the German ICD-10-GM cata$\log$ is not as specific as the ICD-10 Clinical Modification catalog. Although bDMARD usage was identified using the claims data, we can only presume that the medication was administered, as the data only supports receipt and payment. Moreover, bDMARD prescriptions were assessed only for the outpatient setting. We were unable to determine the cause of treatment discontinuation, which could include adverse events, lack of efficacy, or clinical remission. We also cannot rule out the possibility that different treatment intervals might influence persistence, although this is more likely in the short term. For instance, employing a three-month treatment interval for 
ustekinumab and switching patients who do not adequately respond to treatment initiation to second-line treatment after a watch-and-wait period of only three months would lead to an excessive persistence value. As there was only one switcher in the ustekinumab population, we consider the magnitude of this potential bias to be small. Finally, new biologics such as ixekizumab, brodalumab, guselkumab, tildrakizumab, risankizumab, and tofacitinib were excluded from the analysis as data for these agents during the study period were unavailable. Further research can provide insights into these bDMARDs and tsDMARDs as well.

\section{CONCLUSION}

One-year persistence rates for biologics prescribed to patients with PsA in a German realworld setting were modest, but they varied depending on the bDMARD considered. This study may aid clinicians and policy makers by showing that optimal persistence can be achieved through careful treatment selection.

\section{ACKNOWLEDGEMENTS}

The analyses were performed in collaboration with Prof. Dr. Wolfgang Greiner and the Institute for Applied Health Research Berlin (InGef).

Funding. The study was funded by JanssenCilag, Neuss, Germany. The sponsor is also funding the journal's Rapid Service Fee.

Medical Writing. We thank Leo J. Philip Tharappel from Siro Clinpharm Pvt. Ltd. for providing medical writing and editorial assistance.

Authorship. All named authors meet the International Committee of Medical Journal Editors (ICMJE) criteria for authorship for this article, take responsibility for the integrity of the work as a whole, and have given their approval for this version to be published.
Authorship Contributions. The analyses were performed in collaboration with Prof. Dr. Wolfgang Greiner and the Institute for Applied Health Research Berlin (InGef).

Disclosures. Philipp Sewerin received consulting and lecture fees from AXIOM Health, AMGEN, AbbVie, Biogen, Bristol-Myers Squibb, Celgene, Chugai Pharma Marketing Ltd./Chugai Europe, Deutscher Psoriasis-Bund, Gilead Sciences, Hexal Pharma, Janssen-Cilag, Johnson \& Johnson, Lilly, medi-login, Mediri GmbH, Novartis Pharma, Onkowissen $\mathrm{GmbH}$, Pfizer, Roche Pharma, Rheumazentrum Rhein-Ruhr, Sanofi-Genzyme, Spirit Medical Communication, Swedish Orphan Biovitrum, and UCB Pharma; and research funding from Deutsche Forschungsgesellschaft (DFG), Bundesministerium für Bildung und Forschung (BMBF), European Union (EU), AMGEN, AbbVie, BMS, Celgene, Chugai, Deutscher Psoriasis-Bund, Janssen-Cilag, Lilly, Novartis, Roche, and UCB Pharma. Kathrin Borchert and Dominic Meise received funding for this study from JanssenCilag. Matthias Schneider received consulting and lecture fees from MSD, Abbott, AbbVie, Pfizer, GlaxoSmithKline, UCB, Roche, AstraZeneca, Lilly, Janssen-Cilag, Sanofi-Aventis, Chugai, Celgene, Novartis, Boehringer Ingelheim, and Bristol-Myers Squibb. Jörg Mahlich is an employee of Janssen-Cilag and may have stock/stock options.

Compliance with Ethics Guidelines. This retrospective study was based on an anonymized routine dataset obtained from the research database of the Institute of Applied Health Research Berlin (InGef). The authors received permission to use this private dataset.

Data Availability. The datasets analyzed during the current study are available from the corresponding author on reasonable request.

Open Access. This article is licensed under a Creative Commons Attribution-NonCommercial 4.0 International License, which permits any non-commercial use, sharing, adaptation, distribution and reproduction in any medium or format, as long as you give appropriate credit 
to the original author(s) and the source, provide a link to the Creative Commons licence, and indicate if changes were made. The images or other third party material in this article are included in the article's Creative Commons licence, unless indicated otherwise in a credit line to the material. If material is not included in the article's Creative Commons licence and your intended use is not permitted by statutory regulation or exceeds the permitted use, you will need to obtain permission directly from the copyright holder. To view a copy of this licence, visit http://creativecommons.org/licenses/by$\mathrm{nc} / 4.0 /$.

\section{REFERENCES}

1. Ritchlin CT, Colbert RA, Gladman DD. Psoriatic arthritis. N Engl J Med. 2017;376:957-70.

2. McArdle A, Pennington S, FitzGerald O. Clinical features of psoriatic arthritis: a comprehensive review of unmet clinical needs. Clin Rev Allergy Immunol. 2018;55:271-94.

3. Sewerin P, Brinks R, Schneider M, et al. Prevalence and incidence of psoriasis and psoriatic arthritis. Ann Rheum Dis. 2019;78:286-7.

4. Taylor WJ. Impact of psoriatic arthritis on the patient: through the lens of the WHO International Classification of Functioning, Health, and Disability. Curr Rheumatol Rep. 2012;14:369-74.

5. Gudu T, Kiltz U, de Wit M, et al. Mapping the effect of psoriatic arthritis using the International Classification of Functioning. Disabil Health J Rheumatol. 2017;44:193-200.

6. Jacob C, Meier F, Neidhardt K, et al. Epidemiology and costs of psoriatic arthritis in Germany-a retrospective claims data analysis. Value Health. 2016;19:A566.

7. Sondermann W, Ventzke J, Matusiewicz D, et al. Analysis of pharmaceutical care in patients with psoriatic arthritis using statutory health insurance data. J Dtsch Dermatol Ges. 2018;16:285-94.

8. Ogdie A, Coates LC, Gladman DD. Treatment guidelines in psoriatic arthritis. Rheumatology (Oxford). 2020;59:i37-46.

9. Gossec L, Baraliakos X, Kerschbaumer A, et al. EULAR recommendations for the management of psoriatic arthritis with pharmacological therapies: 2019 update. Ann Rheum Dis. 2020;79:700-12.

10. D'Angelo S, Tramontano G, Gilio M, et al. Review of the treatment of psoriatic arthritis with biological agents: choice of drug for initial therapy and switch therapy for non-responders. Open Access Rheumatol. 2017;9:21-8.

11. Cramer JA, Roy A, Burrell A, et al. Medication compliance and persistence: terminology and definitions. Value Health. 2008;11:44-7.

12. Oelke KR, Chambenoit O, Majjhoo AQ, et al. Persistence and adherence of biologics in US patients with psoriatic arthritis: analyses from a claims database. J Comp Eff Res. 2019;8:607-21.

13. Lyu R, Govoni M, Ding Q, et al. Treatment persistence among patients with rheumatoid disease (RA, AS, PsA) treated with subcutaneous biologics in Germany. Rheumatol Int. 2016;36:143-53.

14. Ribeiro da Silva MR, Ribeiro Dos Santos JB, Maciel Almeida A, et al. Medication persistence for psoriatic arthritis in a Brazilian real-world setting. Future Sci OA. 2019;5:369.

15. Jacob L, Chevalier T, Kostev K. Persistence with biological drugs in patients treated in rheumatology practices in Germany. Rheumatol Int. 2019;39: 525-31.

16. Statistisches Bundesamt (DESTATIS). Ergebnisse der Bevölkerungsfortschreibung auf Grundlage des Zensus 2011. Wiesbaden: Statistisches Bundesamt (DESTATIS); 2019. https://www.destatis.de/DE/ Themen/Gesellschaft-Umwelt/Bevoelkerung/ Bevoelkerungsstand/_inhalt.html. Accessed 30 Jun 2020

17. Andersohn F, Walker J. Characteristics and external validity of the German Health Risk Institute (HRI) Database. Pharmacoepidemiol Drug Saf. 2016;25: 106-9.

18. Jacob J, Schmedt N, Hickstein L, et al. Comparison of approaches to select a propensity score matched control group in the absence of an obvious start of follow up for this group: an example study on the economic impact of the DMP bronchial asthma. Gesundheitswesen. 2020;82:S151-7.

19. Kossack N, Schindler C, Weinhold I, et al. German claims data analysis to assess impact of different intraocular lenses on posterior capsule opacification and related healthcare costs. Z Gesundh Wiss. 2018;26:81-90.

20. Charlson ME, Pompei P, Ales KL, et al. A new method of classifying prognostic comorbidity in 
longitudinal studies: development and validation. J Chronic Dis. 1987;40:373-83.

21. Sruamsiri R, Kameda H, Mahlich J. Persistence with biological disease-modifying antirheumatic drugs and its associated resource utilization and costs. Drugs Real World Outcomes. 2018;5:169-79.

22. Mahlich J, Alba A, Hadad LE, et al. Drug survival of biological therapies for psoriasis treatment in Germany and associated costs: a retrospective claims database analysis. Adv Ther. 2019;36:1684-99.

23. Mahlich J, Sruamsiri R. Persistence with biologic agents for the treatment of rheumatoid arthritis in Japan. Patient Prefer Adherence. 2016;10:1509-19.

24. WHO Collaborating Centre for Drug Statistics Methodology. ATC/DDD Index 2020. Oslo: WHO Collaborating Centre for Drug Statistics Methodology; 2019. Available from: https://www.whocc.no/ atc_ddd_index/. Accessed 27 May 2020

25. Walsh JA, Adejoro O, Chastek B, et al. Treatment patterns among patients with psoriatic arthritis treated with a biologic in the United States: descriptive analyses from an administrative claims database. J Manag Care Spec Pharm. 2018. https:// doi.org/10.18553/jmcp.2018.17388.

26. Murage MJ, Tongbram V, Feldman SR, et al. Medication adherence and persistence in patients with rheumatoid arthritis, psoriasis, and psoriatic arthritis: a systematic literature review. Patient Prefer Adherence. 2018;12:1483-503.

27. Walsh JA, Cai Q, Lin I, et al. Real-world 2-year treatment patterns among patients with psoriatic arthritis treated with injectable biologic therapies. Curr Med Res Opin. 2020;36:1245-125.

28. Arnold T, Schaarschmidt ML, Herr R, et al. Drug survival rates and reasons for drug discontinuation in psoriasis. J Dtsch Dermatol Ges. 2016;14: 1089-99.

29. Umezawa Y, Nobeyama Y, Hayashi M, et al. Drug survival rates in patients with psoriasis after treatment with biologics. J Dermatol. 2013;40:1008-13.

30. Yayli S, Baykal Selcuk L, Aksu Arica D, et al. Drug survival of biologic treatments in Turkish patients with psoriasis. Dermatol Ther. 2020;33:e13917.

31. Sruamsiri R, Iwasaki K, Tang W, et al. Persistence rates and medical costs of biological therapies for psoriasis treatment in Japan: a real-world data study using a claims database. BMC Dermatol. 2018;18:5.

32. Menter A, Papp KA, Gooderham M, et al. Drug survival of biologic therapy in a large, disease-based registry of patients with psoriasis: results from the
Psoriasis Longitudinal Assessment and Registry (PSOLAR). J Eur Acad Dermatol Venereol. 2016;30: 1148-58.

33. Egeberg A, Ottosen MB, Gniadecki R, et al. Safety, efficacy and drug survival of biologics and biosimilars for moderate-to-severe plaque psoriasis. Br J Dermatol. 2018;178:509-19.

34. Iskandar IYK, Warren RB, Lunt M, et al. Differential drug survival of second-line biologic therapies in patients with psoriasis: observational cohort study from the British Association of Dermatologists Biologic Interventions Register (BADBIR). J Invest Dermatol. 2018;138:775-84.

35. Warren RB, Smith CH, Yiu ZZN, et al. Differential drug survival of biologic therapies for the treatment of psoriasis: a prospective observational cohort study from the British Association of Dermatologists Biologic Interventions Register (BADBIR). J Invest Dermatol. 2015;135:2632-40.

36. Lin PT, Wang SH, Chi CC. Drug survival of biologics in treating psoriasis: a meta-analysis of realworld evidence. Sci Rep. 2018;8:16068.

37. Carrascosa JM, van Doorn MB, Lahfa $M$, et al. Clinical relevance of immunogenicity of biologics in psoriasis: implications for treatment strategies. J Eur Acad Dermatol Venereol. 2014;28:1424-30.

38. Stober C, Ye W, Guruparan T, et al. Prevalence and predictors of tumour necrosis factor inhibitor persistence in psoriatic arthritis. Rheumatology (Oxford). 2018;57:158-63.

39. Wei W, Knapp K, Wang L, et al. Treatment persistence and clinical outcomes of tumor necrosis factor inhibitor cycling or switching to a new mechanism of action therapy: real-world observational study of rheumatoid arthritis patients in the United States with prior tumor necrosis factor inhibitor therapy. Adv Ther. 2017;34:1936-52.

40. Simpson RJ Jr, Mendys P. The effects of adherence and persistence on clinical outcomes in patients treated with statins: a systematic review. J Clin Lipidol. 2010;4:462-71.

41. Rajzbaum G, Grados F, Evans D, et al. Treatment persistence and changes in fracture risk, back pain, and quality of life amongst patients treated with teriparatide in routine clinical care in France: results from the European Forsteo Observational Study. Joint Bone Spine. 2014;81:69-75.

42. Ruyssen-Witrand A, Perry R, Watkins C, et al. Efficacy and safety of biologics in psoriatic arthritis: a systematic literature review and network metaanalysis. RMD Open. 2020;6:e001117. 
43. Rahman P, Puig L, Gottlieb AB, et al. Ustekinumab treatment and improvement of physical function and health-related quality of life in patients with psoriatic arthritis. Arthritis Care Res (Hoboken). 2016;68:1812-22.

44. Olivieri I, Cortesi PA, de Portu S, et al. Long-term costs and outcomes in psoriatic arthritis patients not responding to conventional therapy treated with tumour necrosis factor inhibitors: the extension of the Psoriatic Arthritis Cost Evaluation (PACE) study. Clin Exp Rheumatol. 2016;34:68-75.

45. Tillett W, Shaddick G, Jobling A, et al. Effect of antiTNF and conventional synthetic disease-modifying anti-rheumatic drug treatment on work disability and clinical outcome in a multicentre observational cohort study of psoriatic arthritis. Rheumatology (Oxford). 2017;56:603-12.

46. Iragorri N, Hofmeister M, Spackman E, et al. The effect of biologic and targeted synthetic drugs on work- and productivity-related outcomes for patients with psoriatic arthritis: a systematic review. J Rheumatol. 2018;45:1124-30.
47. Burgos-Pol R, Martinez-Sesmero JM, Ventura-Cerda $\mathrm{JM}$, et al. The cost of psoriasis and psoriatic arthritis in 5 European countries: a systematic review. Actas Dermosifiliogr. 2016;107:577-90.

48. D'Angiolella LS, Cortesi PA, Lafranconi A, et al. Cost and cost effectiveness of treatments for psoriatic arthritis: a systematic literature review. Pharmacoeconomics. 2018;36:567-89.

49. Belhassen M, Tubach F, Hudry C, et al. Impact of persistence with tumour necrosis factor inhibitors on healthcare resource utilization and costs in chronic inflammatory joint diseases. $\mathrm{Br} \mathrm{J}$ Clin Pharmacol. 2021;87:163-77.

50. Taylor W, Gladman D, Helliwell P, et al. Classification criteria for psoriatic arthritis: development of new criteria from a large international study. Arthritis Rheum. 2006;54:2665-73.

51. Coates LC, Kavanaugh A, Mease PJ, et al. Group for Research and Assessment of Psoriasis and Psoriatic Arthritis 2015 Treatment Recommendations for Psoriatic Arthritis. Arthritis Rheumatol. 2016;68: 1060-71. 